\title{
Erratum to: Structural Relationships Between Genetically Closely Related O-Antigens of Escherichia coli and Shigella spp.
}

\author{
Y. A. Knirel ${ }^{1, a *}$, Chengqian Qian $^{2}$, A. S. Shashkov ${ }^{1}$, O. V. Sizova ${ }^{1}$, E. L. Zdorovenko ${ }^{1}$, \\ O. I. Naumenko ${ }^{1}$, S. N. Senchenkova ${ }^{1}$, A. V. Perepelov ${ }^{1}$, and Bin Liu ${ }^{2, b}$ \\ ${ }^{1}$ Zelinsky Institute of Organic Chemistry, Russian Academy of Sciences, 119991 Moscow, Russia; fax: +7 (499) 135-5328 \\ ${ }^{2}$ Nankai University, TEDA Institute of Biological Sciences and Biotechnology, \\ Key Laboratory of Molecular Microbiology and Technology, Ministry of Education, 300457 Tianjin, China \\ ae-mail:yknirel@gmail.com \\ ${ }^{b}$ e-mail: striker198126@aliyun.com \\ Received February 3, 2016 \\ Revision received March 13, 2016
}

DOI: $10.1134 / \mathrm{S} 0006297918110123$

The original article can be found online at https://doi.org/10.1134/S0006297916060067.

Errors have been found in polysaccharide structures on pages 603 (Fig. 3), 606 (Figs. 13-15) and 607 (Fig. 17). The following are the correct structures.

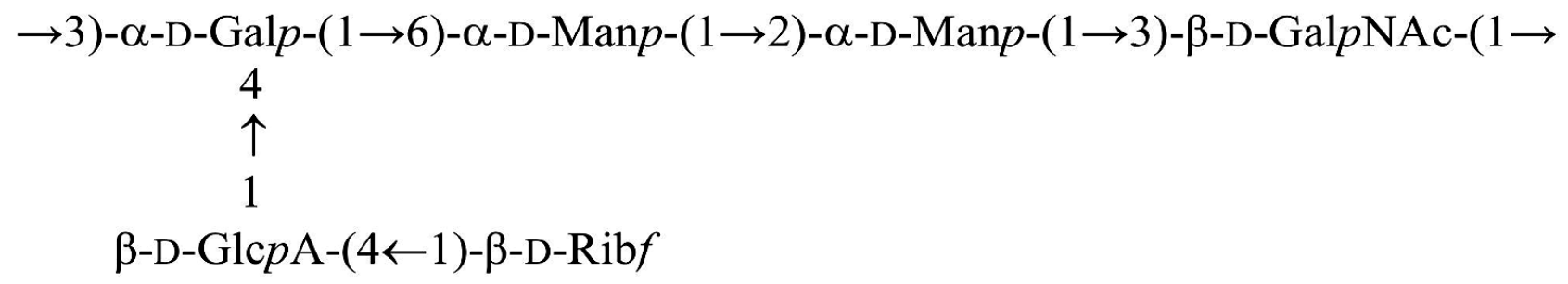

Fig. 3. O-polysaccharide of E. coli $\mathrm{O} 183$ and S. boydii type 10 [13].

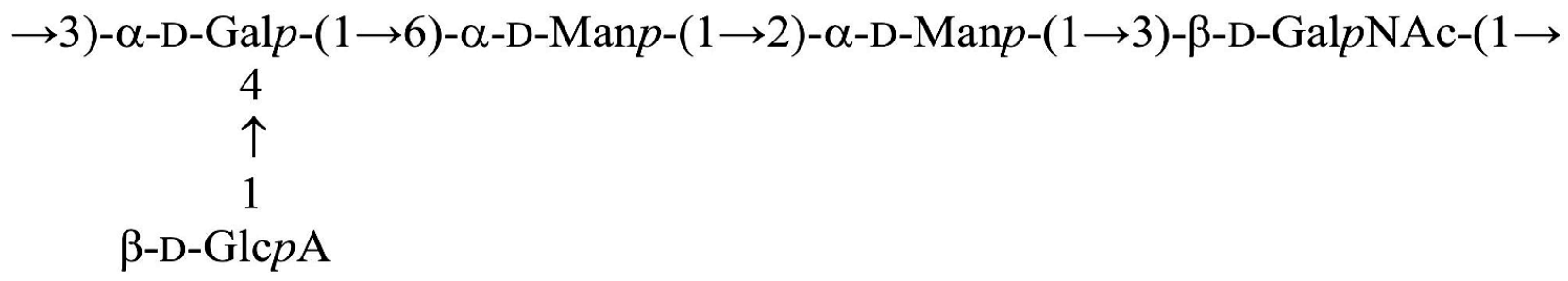

Fig. 13. O-polysaccharide of $S$. boydii type 6 [13]. 


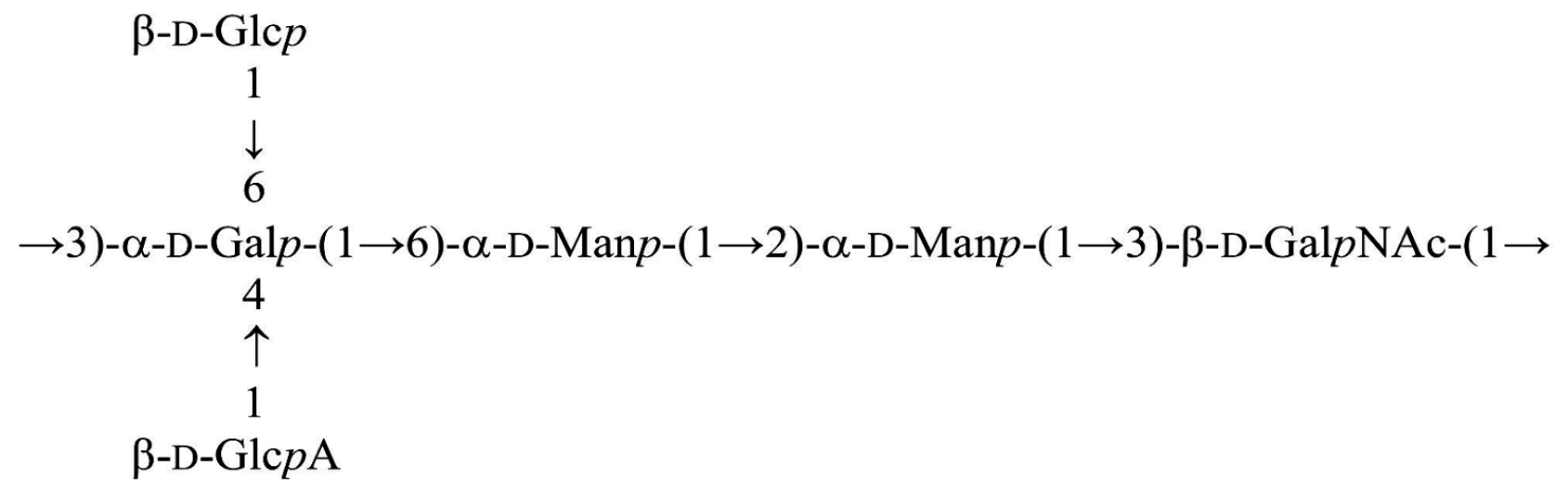

Fig. 14. O-polysaccharide of E. coli O169 [7].

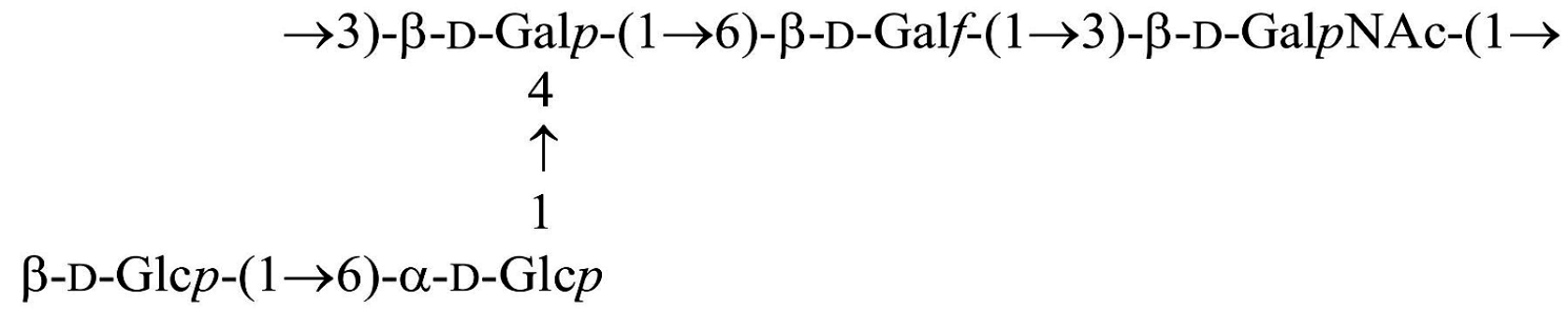

Fig. 15. O-polysaccharide of E. coli $\mathrm{O} 124$ [4] and S. dysenteriae type 3 [4].

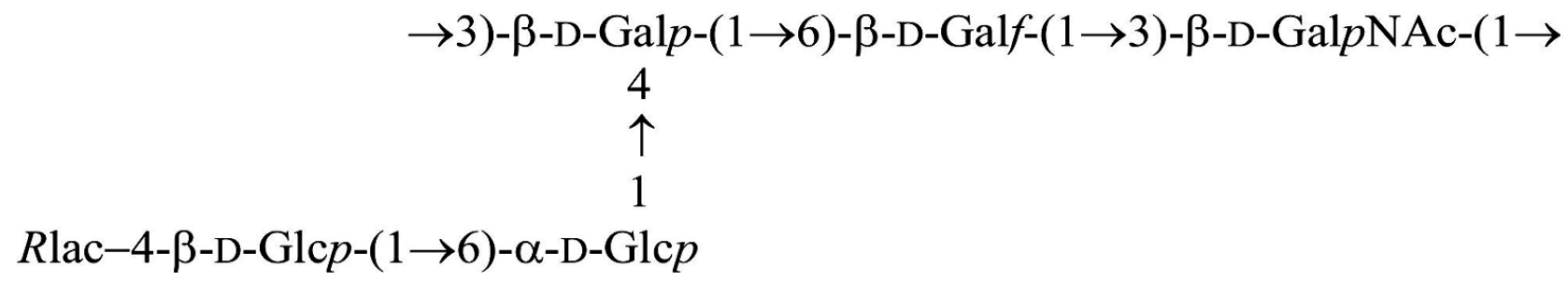

Fig. 17. O-polysaccharide of E. coli O164 [4]. 